\title{
13455
}

\section{ABSORPTIVE CAPACITY IN PRACTICE: \\ PRELIMINARY EVIDENCE FROM THE ADDITION OF A SENIOR TEAM \\ MEMBER}

\section{INTRODUCTION}

The manner in which knowledge is assimilated, retained, and distributed within an organization represents an integral element of how that organization functions and performs. This is particularly true of knowledge retained at a management or strategic decision-making level (Hambrick \& Mason, 1984). The concept of absorptive capacity (ACAP) - originally defined by Cohen and Levinthal (1990: 128) as 'the ability of a firm to recognize the value of new, external information, assimilate it, and apply it to commercial ends' - has emerged as a popular basis by which to explain knowledge flows between and within organizations. A vast number of re-conceptualizations and empirical applications of the ACAP concept are now evident throughout the scholarly fields related to management and organization studies. However, the speed of proliferation of these applications has raised concerns that, rather than extending our knowledge of the underlying mechanics of knowledge absorption, abstracted ACAP principles are now being taken for granted as a definitive approach to study (Van Den Bosch, Van Wijk, \& Volberda, 2006). Lane, Koka, and Pathak (2006) contend that the ACAP concept has become reified; that is, its popular usage has elevated its status beyond that of a conceptualization to the point where it is often treated as a defined feature of organizational behavior. Researching organizational knowledge assimilation on these terms can be damaging to the validity of knowledge claims (Volberda, Foss, \& Lyles, 2010), not least because it encourages the study of complicated organizational phenomena through highly abstracted 'grand theories'. Indeed, many scholars contend that ACAP is less a set of strategically defined knowledge-absorbing activities, and more a conceptual label given to the dynamic interaction of a multitude of individual behaviors, social interactions, and 


\section{5}

organizational measures (Van Den Bosch et al., 2006; Volberda et al., 2010). It is here, on the dynamic interactions that construct and maintain ACAP, that our study places its focus.

The difficulties faced in empirically examining organizational ACAP have been exemplified by the use of quantifiable measures, such a $R \& D$ intensity, as the primary means to gauge knowledge flow (Lane et al., 2006; Lewin, Massini, \& Peeters, 2011). Notable reconceptualizations of ACAP from Lane et al (2001) Lane, Salk, and Lyles (2001) and Zahra and George (2002) have made important contributions in distinguishing more specific dimensions of ACAP. The reconceptualized dimensions detailed in these influential works continue to form the basis for data collection and analysis in new empirical studies, where ACAP principles are utilized to examine a variety of phenomena. Recent examples include the work of Patton (2013), who investigated new technology-based firms and the absorption of knowledge from business incubators, or of McAdam, Antony, Kumar, and Hazlett (2011), who applied Zahra and George's (2002) dimensions to examine the assimilation of Six Sigma processes within small to medium sized enterprises (SMEs). Such articles typify the popular tendency for researchers to address ACAP from an organizational or business unit level only (Volberda et al., 2010), where focus is placed on formal organizational approaches, systems, or standard operating procedures aimed at the extraction and embedding of knowledge. However, this approach deviates from one of the fundamental principles of ACAP; namely that it is a multi-level, not a single level, construct (Cohen \& Levinthal, 1990). As a consequence of this, ACAP "should be studied at the individual, unit, firm, and interfirm level of analysis" (Volberda et al., 2010: 937). Here, individual actions and collective social interaction represent the means by which routines are performed. There, in turn, both shape and define, and are shaped and defined by, organizational-level ACAP antecedents. In this sense, "there is no organization level ACAP without individual level ACAP" (Volberda et al., 2010: 937). 


\section{5}

Recognizing this, our study aims to examine ACAP from the 'ground up' by focusing on how the microfoundations of organizational routines, displayed by individual and interactive performances, interact with organizational features to ultimately construct and maintain what we, as researchers, would identify as an organization's absorptive capacity. Our approach builds on Lewin et al's (2011) identification of organizational routines as the building blocks of organizational capabilities, and their definition of ACAP as a dynamic capability. However, where Lewin et al's (2011) model is conceptual and static, our study ultimately aims to capture the dynamics of multilevel routine interaction as they happen over time. Our current article presents the preliminary findings of this overall study. These findings are based on initial pilot interviews. This allows us to offer an early conceptualization of activities occurring across ACAP levels. The paper represents the foundation of a future study, which aims to collect detailed research diaries, with daily interactions and performances of routines over a three-month period. This will allow findings to portray the maintenance and construction of ACAP in its natural state of flux.

We define routines as "regular patterns of activity that emerge or are created to resolve specific organizational problems" (Jones \& Craven, 2001: 277). Microfoundations represent the building blocks of these routines (Felin, Foss, Heimeriks, \& Madsen, 2012). We follow the rationale of recent work by Dacin, Munir, and Tracey (2010) who examined performance of rituals at Cambridge University formal dinners as a means to portray the maintenance of the British class structure as an institution. In a similar vein, a central logic underpinning our study is that the free-flow of knowledge fundamentally takes places at individual, interactive, and performative level (Felin et al., 2012; Zahra \& George, 2002) and consequently it is only on this micro level that the assimilation of knowledge can really be observed. We attempt to forge a link between the interactive and organizational antecedents of ACAP, the lack of which has undermined the explanatory power of the concept (Hotho, Becker - Ritterspach, \& 


\section{5}

Saka - Helmhout, 2012). In doing so we answer research calls for empirical study of and further theoretical development concerning how aspects such as the actions of individual agents, particularly managers, can shape organizational ACAP (Volberda et al., 2010).

To illustrate the dynamics of ACAP antecedents, we examine the recruitment of a new member in to an entrepreneurial management team (EMT). In this sense, our study focuses on "inward-looking" ACAP (Cohen \& Levinthal, 1990: 133), which entails the internal sharing of knowledge absorbed from the outside, rather than knowledge shared at an interorganizational level. As an illustrative context, the phenomenon of EMT member entry reflects observations originally made by Cohen and Levinthal (1990) regarding the 'buying' of ACAP though recruitment of new personnel or through corporate acquisition (Van den Bosch et al, 2003). The addition of a new member represents a means by which existing management can augment their knowledge resources (Sandberg, 1992; Ucbasaran et al, 2003). Thus, this period of managerial flux represents a highly appropriate example in which firms must actively attempt to assimilate and embed incoming knowledge in order that they can realize the benefits of recruitment.

The principle rationale for team-managed firms is that they can gain an advantage by combining the knowledge and resources of multiple managers (Kamm et al, 1990; Cooper et al, 1994). This gives some explanation as to why the majority of entrepreneurial ventures are managed by teams of people rather than by a single entrepreneur (Cooper and Daily, 1997; Harrison et al, 2004). Furthermore, investigation of the phenomenon of EMT member entry raises important implications for management team development and demography literature. In their study of EMT member addition, Forbes et al (2006) underscore a common weakness in many existing examinations of team development, where the addition of a new member is examined up to the 'point of entry' only. The assumption here is that, if a new member holds 


\section{5}

knowledge that is useful or complimentary to the recruiting team, then the addition of that member will result in positive benefits for existing management. However, this view falsely assumes that potential knowledge will act as realized knowledge once the new member enters the EMT. In contrast, empirical research suggests that activities occurring after the 'point of entry' can greatly influence the effectiveness of recruitment. One example of such mediating influence originates from the affective conflict literature, which highlights member dynamics and the impacts that conflict can have on damaging team performance, or on positively encouraging innovation through variety of opinion or perspective (Ensley et al, 2007; Page West, 2007). Similarly, our study offers further insight to post-entry knowledge utilization. The implication here is that the successful entry of a new member in to an entrepreneurial team is, at least partially, a function of the existing unit's absorptive capacity.

\section{THEORETICAL CONTEXT}

\section{The Construction and Maintenance of Absorptive Capacity}

Absorptive capacity has proven to be an enduring theoretical approach for understanding the acquisition, assimilation, transformation and exploitation of knowledge, yet, despite this, "few studies have captured the richness and multidimensionality of the concept" (Jansen, Van Den Bosch, \& Volberda, 2005: 999). This is perhaps partly owing to the intangible nature of knowledge and the subsequent utilization of crude proxy measures in early studies that typically equated R\&D spend or patent volume with levels of organizational ACAP. While useful for the examination of core activities within organizations such as technology-based firms, this approach is far from representative of the plethora of interacting antecedents that can underpin ACAP (Lane et al., 2006; Spithoven, Clarysse, \& Knockaert, 2011). Following 


\section{5}

Cohen and Levinthal's initial theorization $(1989,1990)$ several attempts have been made to both refine the construct and overcome difficulties in operationalizing empirical research. Zahra and George (2002) distinguish between potential absorptive capacity (PAC) which involves dimension that utilize external knowledge and realized absorptive capacity (RAC) which derives new insights from combining new and existing knowledge. The authors also introduce the notion that each dimension of ACAP consists of bundled organizational routines which, when combined, form a distinct and hard to replicate source of competitive advantage.

This focus on organizational routines has underpinned attempts to open the 'black box' of knowledge absorption. In particular, Lewin et al. (2011) contribute significantly to this by drawing on institutional theory and evolutionary economics (Feldman \& Pentland, 2003; Nelson \& Winter, 1982) to identify a series of internal and external meta-routines they claim are aggregated to create organizational ACAP. These meta-routines are high-level abstracted routines that describe the general purpose of practiced ACAP routines. This model allows for different organizations to practice the meta-routines in an infinite variety of different ways and hence variations in firm performance can be explained by idiosyncrasies in the practical configuration and enactment of these routines. ACAP theorists have also increasingly turned to the dynamic capabilities literature to explain the fluid and temporal nature of capability maintenance and development (Todorova \& Durisin, 2007). This focus on the renewal of, and continuous investment in, skills development and learning traces back to Cohen and Levinthal (1994) while the reflexive relationship with a changing external environment echoes Teece, Pisano, and Shuen (1997) and Teece (2007).

Though recent developments have enriched understanding of ACAP by following a more micro-level and empirical path (Chalmers \& Balan-Vnuk, 2012; Müller-Seitz, 2012), there is 


\section{5}

a general discontent amongst scholars that ACAP is failing to live up to its explanatory potential (Volberda et al., 2010), and worse, that a failure to specify underlying assumptions has impacted upon the validity of some studies (Lane et al., 2006). The general dominance of both conceptual and hypothetico-deductive studies (e.g., Jansen et al., 2005) poses some ontological and epistemological problems for ACAP theory development. Firstly, while scholars recognize that ACAP is a multidimensional construct, few have developed appropriate methods for capturing the interactions between individuals, institutions, organizations and systems where ACAP routines are socially constructed, maintained, adapted and selected. The reduction of ACAP to a manageable set of variables offers obvious theoretical and analytical benefits, however it sacrifices understanding of social and organizational complexity, arguably failing to account for the dynamic and nonlinear nature of capability development. Secondly, a failure to engage with the 'practice' of ACAP means variables that have been hypothetically derived may overlook hitherto unobserved - though critical - mechanisms for coordination, contributing in part to the reification Lane et al. (2006) contends exists within conceptualizations of ACAP. Finally, the failure to contextualize studies of absorptive capacity means the role of agency and the constraining social structure is ignored or at the very least, relegated to a peripheral role. Given the heterogeneity of settings where organizational ACAP can affect the outcome of firm innovation performance (Lewin et al., 2011), it is unproductive to consider the capability something that is the exclusive purview of high-tech firms. Hence, we answer Lane et al. (2006) and Spithoven et al. (2011) calls to explore the development of ACAP in non-R\&D, low-tech though otherwise knowledge-intensive contexts. 


\section{5}

\section{RESEARCH CONTEXT}

\section{The Addition of a New Management Team Member}

The configuration of management level resources within a firm shares a long theorized relationship with organizational growth. The seminal work of Penrose (1959) emphasizes the importance of differentiated forms of entrepreneurial knowledge - related to opportunity recognition and innovation - and managerial knowledge - related to operationalization and exploitation of opportunities - as key determinants of how a firm is able to develop. The relationship between managerial knowledge and organizational performance is also one that characterizes popular lifecycle or stage models of firm growth (Greiner, 1972; Churchill and Lewis, 1983; Quinn and Cameron, 1983). Here, the advancement towards a new growth 'stage' is typically portrayed as a bottleneck, where existing management must be reconfigured in order to facilitate progression. The association is further reflected in the management team demography literature. The upper echelons perspective (Finkelstein \& Hambrick, 1996; Hambrick \& Mason, 1984), which represents an established concept in strategic management literature, posits that the composition of human resources held within a top management team (TMT) will likely determine the strategic choices that underpin the performance of a firm. This perspective has translated well to small business and entrepreneurship research, becoming strongly associated with human capital literature to spawn numerous studies of how the experience of single entrepreneurs (Colombo \& Grilli, 2005; Gimmon \& Levie, 2010) and entrepreneurial teams (Delmar \& Shane, 2006; Eisenhardt, 2013; Ensley \& Hmieleski, 2005) can impact various performance measures, notably firm survival or firm growth. As a consequence, knowledge acquisition and application share a strong affinity with the notion of EMT member entry and its status as a representation of changing managerial configuration (Tehyal, 2012). 


\section{5}

Consistent with this rationale of knowledge accumulation, the principal theoretical perspective underpinning EMT or TMT member entry is that which emphasizes resourceseeking behavior. Under this view, a new member is added to an existing team because their new knowledge is perceived to provide the optimal improvement to existing management resources, relative to the investment (recruitment) cost (Forbes, Borchert, Zellmer - Bruhn, \& Sapienza, 2006). The perspective therefore places significance on rational assessment of the existing team, the identification of knowledge and skills gaps, and optimized search processes to 'fill' those gaps (Sandberg, 1992). A contrasting view is that which explains new member entry as an expression of sociopsychological attraction. Under this stance, members are selected primarily because of a perception that they have a social 'fit' with the existing team. This often has the effect of grouping together members with similar working, educational, or social backgrounds (Byrne, 1971), and is reflected by a number of studies that identify the tendency for shared prior relationships between members of a team (Neiswander et al., 1987; Ruef et al, 2005). Unlike the purely rational, resource-seeking view, this perspective raises considerations for post 'point of entry' functioning of the team. The selection of members with shared values holds strong associations with notions of trust and chemistry between team members; aspects that are likely to positively influence effective dynamics and group cohesion (Forbes et al., 2006). In this sense, recruitment explanations founded in sociopsychological considerations may also, consciously or unconsciously, entail elements of rational foresight regarding how the functioning of the team is likely to impact performance. However, on the other hand, encouraging cultural reinforcement through the hiring of similar members - labeled as the process of homophily (Ruef, Aldrich, \& Carter, 2003) - can tend towards the creation of homogeneously experienced management teams (Neiswander, Bird, \& Young, 1987). The danger here is that the lack of variety in knowledge 


\section{5}

held by team members can stifle creativity and undermine the ability of the team to achieve organizational objectives.

Forbes et al. (2006) argue that while the bulk of literature is underpinned by the implication that new EMT member entry ought to be chosen based on their knowledge and resource contribution, evidence suggests that sociopsychological explanations are more relevant to new member addition as it actually occurs. It does, of course, make sense that, given the impracticality of conducting a purely rational, optimized assessment and selection process, such a process is unlikely to occur in the real world. Aside from considerations of trust and chemistry, there are clear practical considerations surrounding cost of search or the availability of network access to suitable recruits (Neergaard, 2005). That said, it is equally improbable that all considerations of knowledge contribution to identified strategic criteria are removed from the recruitment process. Despite the apparent dichotomy drawn between the two perspectives, a number of researchers concede that elements of both are likely to underpin member addition decisions (Kamm \& Nurick, 1993; Larson \& Starr, 1993) In short, knowledge accumulation remains a definitive aspect of member recruitment, at least in some fashion.

Our preliminary findings focus on one entrepreneurial firm that attempted to expand its services through the addition of a new senior sales consultant. We use an inclusive definition of EMT membership, which emphasizes membership as those who have significant involvement in strategy formation and delivery, rather than demanding them to have "equal financial interest" as with some EMT definitions (Kamm, Shuman, Seeger, \& Nurick, 1990). We argue that because strategic responsibility is more fine grained and occurs more at the ground level of small enterprises, appointed managers are more likely to act as 


\section{5}

entrepreneurial agents (Ucbasaran, Lockett, Wright, \& Westhead, 2003; West, 2007). The firm in question (Firm XYZ) was founded in 2009 as a professional services organization providing consultancy to investment banks, and focusing particularly on the trading and risk management activities. XYZ has seventy employees based in London (HQ), Hong Kong and Sydney with an annual turnover of $£ 6$ million for the financial year 2012/13. As a professional services firm, $\mathrm{XYZ}$ is reliant on continuous recruitment as an integral element of its growth strategy. A senior sales consultant (New Entrant) was recruited in June 2013 in order to manage increased European sales and project delivery

\section{METHODS}

\section{Data Sources}

Pilot interviews were conducted with the CEO of XYZ and a Senior Consultant who started with the company in June 2013. The average time of the interviews was 60 minutes, the interviews were recorded and transcribed verbatim. The selection of participants was driven by "a conceptual question, not by a concern for representativeness" (Miles \& Huberman, 1994: 29). As such, the major concern was examining ACAP from the 'ground up' by focusing on the microfoundations of organizational routines, ideally seeking out those involved in the process and how they interacted with organizational features to construct and maintain XYZ's absorptive capacity. Thus purposive sampling was employed.

There were two interview protocols - one for existing management (CEO) and one for the new entrant. The existing management interview protocol contained questions about the organization, the growth strategies and pre-recruitment information (for example, why and how the new entrant was added, what was expected of them). The new entrant interview protocol included background information, and daily activities undertaken. These interviews 


\section{5}

were supplemented by observations. The observations were undertaken before, during and after the interviews. Specifically, field notes were taken of the office setting, the ambience, the physical layout of the office and employees and the interactions between staff. Field notes were also taken after the interviews and the observations to ensure that no information was lost or forgotten. All the interviews were undertaken in the London office. Finally, to further develop an understanding of XYZ's background we collected company reports, annual reports and online information online from their website and other online resources (magazines, reviews and blogs).

Insert figure 1 about here

\section{Data Analysis}

Our overall approach emphasizes an inductive approach, where the data is encouraged to 'speak for itself' (Cope, 2005). Key here is that our analysis is context specific and aims to portray knowledge absorption as it occurs in the lived world. Our preliminary analysis consisted of a number of steps. First, transcribed interviews were divided in to various identified knowledge application and absorption actions. Next, these actions were coded according to the purpose that they served in supporting ACAP activities. Actions representing similar purposes were then grouped together to form initial first order categories. Interview transcripts were then re-read and re-coded according to these first order categories. We then sought to group first order categories in to theoretically distinct clusters. We did this by attempting to identify common fundamental rationales in each of the first order categories. For example, distinguishing new knowledge application measures from existing knowledge maintenance activities, or defined activities from heuristics. These groupings are represented 


\section{5}

by our second-order categories. Finally, second-order themes followed a similar process to develop aggregate theoretical dimensions, which served as a basis to order the findings. The structure of our data analysis procedure is illustrated in figure 1.

\section{PRELIMINARY FINDINGS}

\section{THE CONSTRUCTION AND MAINTENANCE OF ACAP COMPONENTS}

The impression suggested by some popular accounts of absorptive capacity is one of an identifiable organizational capability that can be applied as a strategic measure. This is then aimed at gaining superior performance through the effective management of knowledge. However, our analysis finds that ACAP is only partially dictated by its organizational level antecedents. The internal flow of organizational knowledge is instead portrayed here as an absolutely intrinsic feature of organizational life, one that permeates all facets of an organization whether it chooses to explicitly employ knowledge absorption activities or not. These multi-level actions are not necessarily those that might typically be associated with new knowledge absorption. In fact, activities key to the construction and maintenance of knowledge can be mundane as well as new and transformational. At best, an organization can encourage favorable conditions for the new knowledge creating and maintaining activities. These may harness and partially direct knowledge flow, without ever fully controlling it. ACAP capabilities are not neatly defined but rather are represented by a constantly morphing and highly interrelated set of individual actions, social interactions, and interpretations of organizational measures. As actions are carried out at a microfoundational level they shape the actions of the organization. Yet, at the same time, the features of the organization partially shape microfoundational and interactive behavior. This shaping and reshaping occurs constantly as organizational practices are performed, translated, revised, and 


\section{5}

communicated. Furthermore, vital ACAP metaroutines - take, for example, sharing knowledge and superior practices (Lewin et al., 2011) - are carried out by activities that take place not just simultaneously but symbiotically across levels. It is this ongoing activity that defines how ACAP is constructed and maintained.

\section{Insert Table 1 about here}

This complexity makes the capturing and conceptualizing of an organization's ACAP somewhat problematic. For instance, cross-sectional data could never hope to depict these perpetually changing and interrelated features, which clearly require an approach capable of capturing a temporal dimension. At this preliminary stage our analysis seeks only to conceptualize key theoretical components of ACAP reflected by our data. It is important to underline that the structure of data presentation utilized here does not imply that the absorption of new member knowledge is a linear process. This structure is used in order to communicate findings in a digestible manner rather than to artificially segment the complexities of ACAP. Therefore, while knowledge absorption may occur in the 'sequence' presented, it also may occur in a different orders as well as having overlapping elements, back-and-forward progression, and feedback from one, or more, aspects to others. The findings present three aggregate theoretical dimensions. First and foremost, the passing of knowledge requires individual agency, which, in this case, rests on the actions of the new entrant. Secondly, practices based on new knowledge must be performed interactively between two or more individuals in order that they can be released from the new entrant and be translated to others. Finally, a variety of organizational measures can act to encourage or block new knowledge practice and how it may or may not be embedded in to the firm. 


\section{5}

\section{Individual Level - Agency}

\section{The Individual Maintenance of Existing Knowledge:}

While the appointment of a new EMT member has associations with the addition of strategically transformational new knowledge, it is through the ongoing practice and completion of existing organizational task demands that existing organizational knowledge stocks are maintained. This represents a key element of how ACAP functions at an individual level. Because existing role demands are based on knowledge already held by the organization, these can be explicitly matched to identified knowledge stock held by the new entrant. The organization is likely to be able to design role specifications and support systems that underpin the ongoing completion of core tasks. Matched effectively, the individual's background affords them the expertise to compete the majority of the role demands that are based on existing organizational knowledge. The ongoing completion of these tasks by the new entrant represents a form of organizational practice or training, which ensures that existing knowledge does not become 'forgotten' by the firm. The remaining role demands that require knowledge beyond that which is held by the new entrant must be learned an individual level. In this sense, a new entrant must bring himself or herself 'up to speed' with the existing organizational knowledge base in order that they can contribute effectively to ongoing knowledge maintenance. This feature reflects the strong conceptual affinity that ACAP shares with learning (Cohen and Levinthal, 1990).

\section{New Knowledge Genesis:}

The application of new knowledge by the new entrant represents a more uncontrollable feature. The difficulty here is that, unlike existing knowledge held by the organization, new, organizationally unknown knowledge is far more difficult to define and to identify in a new entrant. When asked how existing management can ensure that the new entrant would use 


\section{5}

their new knowledge for the good of the company, the CEO simply replied, "We don't know. It's a leap of faith ultimately". As the organization cannot explicitly define the new knowledge being added, specific role demands cannot be defined, and the passage of knowledge from new member to existing management becomes dependent on an element of trust in the individual's actions. Of course, the firm can mediate this risk through various organizational measures, for example through new entrant assessment, job specification design, or the use of incentives. This provides examples of how ACAP must work in tandem across a variety of levels. However, ultimately, an organization (at least, an organization acting within legal boundaries) cannot explicitly force a new member to actively pass on their new knowledge. For the new entrant to act as a means to stimulate variation, the organization is reliant on some form of individual agency. Principally, our analysis indicates that, in order to begin the organizational absorption of new knowledge, the new entrant must go beyond their existing role boundaries to apply new methods or practices. Deviating from accepted organizational practices represents a means by which the new entrant can take ownership of the role (McAllister et al. 2007). In our preliminary study, this appears to be an aspect that the new entrant recognizes as important: "The role is very much what you make of it" (New Entrant Interview).

Ultimately, if the new entrant does not apply their new knowledge they can only, at best, act to maintain existing organizational knowledge through the performance of existing organizational routines. A useful analogy here may be to refer to the difficulties in sharing knowledge under, for example, the principles of Scientific Management (Taylor, 1911) or MacDonalization (Ritzer, 1983, 1998). Here, the extreme emphasis on standardization and on the individual's performance of tightly specified roles both act to heavily reinforce existing organizational knowledge, as well as to encourage control. Yet, equally, these features stifle 


\section{5}

new knowledge application. By contrast, the extraction of new entrant knowledge in our example is dependent on the individual being able to interpret tasks, find their own solutions, and apply these to bigger picture strategy. Our preliminary analysis reflects these types of new practice in a number of forms. For example, there are role aspects that are "very reliant on my past experience" (New Entrant). In these cases, the new entrant draws on their existing knowledge bank and prior experience to perform known practices within the new organizational setting. Alternatively, our analysis highlights how the new entrant can perform planned or unplanned variations to existing organizational practices. Again, the prior experience of the new entrant may be key in acting as a sensemaking frame through which they interpret key practices and how these fit with overall strategy (Gioia \& Chittipeddi, 1991). Finally, practice variations emerge from the development and application of various forms of intuitive, heuristic-based measures.

\section{Interactive Level - Translation}

\section{New Knowledge Translation Through Practice:}

New knowledge applied by an individual is precarious and can be easily removed from the organization. In order for the mechanics of ACAP to function, and for knowledge to flow in to the organization, that knowledge must somehow be communicated to others. Our analysis indicates that for applied new knowledge to begin this process of translation to others, an effective new practice must firstly become recognized. In the case of our pilot study, a form of 'leading by example' by the new entrant acted as the catalyst for initial recognition by other members of the organization. The new entrant's knowledge application, which concerned the creation of new customer service procedures for a consultancy client, firstly became visible through a mutual sense that the practice was valuable and that it yielded results. Consequently, others within the immediate work group imitated and repeated 


\section{5}

elements of the practice. More explicitly, deliberate translation activities, such as job shadowing and peer-training (Chalmers \& Balan-Vnuk, 2012), were undertaken. These interactive behaviors emerged as a key means by which person-specific, tacit knowledge could be communicated and made understandable by others in the immediate working environment. Thus, interaction and knowledge translation were central to underpinning how micro behaviors began emerge as organizational routines.

\section{Codification of Knowledge for Communication:}

The mechanisms discussed above reflect one of Lewin et al's (2011) internal metaroutines sharing knowledge and superior practice - as it occurs on a local interactive level. However, for the diffusion of new knowledge practices to take place over a wider ranging interactive level, our analysis suggests that they are likely to go through some form of codification process. Firstly, our preliminary data underlines the importance of naming or labeling of new practices. Applications of new knowledge that have been collectively performed and refined at a local level can remain precarious, but by allocating a label to these practices collective awareness of them is increased and communication made easier. This represents a key step in legitimizing new knowledge and in elevating the status of a new routine (Zollo \& Winter, 2002). In turn, definitive labels aided the formal recording of new routines. Our data indicates that formal reporting measures played a central part in how new practices were communicated, assessed, and amended by other relevant actors within the organization. Formalization served to summarize the application of new knowledge and make it digestible for dissemination.

\section{Organizational Refreshing and Updating:}

The communication of practices based on new knowledge was not simply a one-off event. Instead, our analysis emphasized the importance of continuous communication and feedback. 


\section{5}

Just as the application of existing knowledge must be performed on an ongoing basis at the level of the individual, the continuous refreshing and updating of routines at an interactive level also emerged as key to knowledge maintenance. Our analysis indicates that proactive and ongoing discussions and the various means that these were communicated through was key in preventing knowledge from becoming 'stale'. In our preliminary case, formal reporting was not only considered to be a procedure, but was, as the CEO put it "a habit to acquire". The habitual updating of applied knowledge took place through a number of means. Firstly, there were the technology-based communication tools, for example email, smartphones, and group messenger platforms. However, it was primarily through social interactions - office chats, lunches, coffees, and after work drinks - that the ongoing maintenance of knowledge took place at an interactive level. In our case, technical mechanisms were considered to be important in relaying factual information, but it was through direct social interaction that the sharing and refining of more complex ideas often took place. The new entrant examined here placed significant emphasis on social communication as a means of refreshing knowledge applications, and proactively set up numerous social gatherings with employees and with senior management. These gatherings also offered the means for informal feedback, often taking the form of a 'pat on the back' or 'quiet word of encouragement' on how new knowledge applications were being received. These measures worked in tandem with more formalized assessments of how practices fitted with overall strategic goals.

\section{Organizational Level - Encouraging and Embedding}

Although it has been identified that the organization is ultimately reliant on individual and interactive behaviors to drive ACAP activities, our analysis also highlights how various measures applied at organizational level can either support or hamper knowledge flow. Thus, 


\section{5}

the final element of how ACAP is maintained largely concerns the level of commitment and support to knowledge-absorption at a strategic level (Feldman \& Pentland, 2003).

The majority of the organizational measures in evidence here appear to be related to the supporting and reinforcing of particular organizational norms that the senior management of the firm hopes to perpetuate. Recent work by Chalmers and Balan-Vnuk (2012) found that ACAP routines evident in social enterprises were, to a significant extent, driven by the overall social mission of the organization. Similarly, the dominant organizational expectations and norms of our case are seen to drive the measures that are taken and the results these are designed to achieve. As such, it is helpful to outline the organizational expectations identified through our analysis. The first of these relates to the promotion of entrepreneurial, or profit-seeking, behavior across all facets of the organization. Particular language is used to distinguish "budget spenders" (CEO interview) - describing an 'employee' mentality noted in someone that works in a large organization - with those who have "commercial awareness", and are able to attach their actions to the overall goals of the company. A second element emphasizes competitive behavior and a 'survival of the fittest' mentality throughout the organization. Organizational measures are designed to create a performance-driven environment where management and employees with a "chip of their shoulder" (CEO interview) thrive. This is supported most notably through the provision of financial incentives, which encouraged new knowledge application through a bonus and profit sharing scheme. Finally, organizational norms emphasized autonomy and creativity, where "not going by the book is very much encouraged" (New Entrant interview). A variety of organizational measures designed to support knowledge creation in line with these norms are noted throughout the data. 


\section{5}

\section{Systematically Supporting New Knowledge Creation:}

The organization was able to support the creation and assimilation of new knowledge through fundamental structural measures. Some of these were evident even from the early stages of new entrant recruitment. In a prominent example, the firm used the recruitment and interview process as a vetting strategy designed to assess the new entrant's attitude towards applying new knowledge and implementing new solutions. Here, the interview placed overwhelming emphasis on evaluating how the new entrant was likely to fit with firm ethos (entrepreneurial, self-starter, competitive, profit-driven) rather than assessing defined functional skills or experience, which were secondary considerations. In this way, the interview process represented a key organizational level ACAP antecedent; one that attempted to filter out those candidates likely to actively pursue knowledge sharing activities. Here, existing management appeared to have recognized that there was little value in recruiting a new entrant with the requisite functional skills if they a) did not have a disposition towards applying their knowledge to new solutions, or b) were unable to utilize their functional skills in a way that was compatible with the entrepreneurial strategy of the firm. The CEO noted that the decision to recruit was a "very personal judgement call", with the ultimate question being "do I trust the person in front of me to share the same beliefs as me?" In this sense, recruitment decisions appear to have been driven heavily by socio-psychological considerations, through which the assessment of chemistry and cultural fit could evaluate the likely extent knowledge-sharing agency that would be applied at an individual and interactive level.

A second prominent organizational level feature related to the design of the new entrant role. Our preliminary study underlined that this role was loosely designed, with a wide scope for task interpretation. The flexibility of role parameters appeared to be a deliberate measure aimed at encouraging an environment where creative solutions and new knowledge 
applications were accepted. This offered a particular contrast to the previous roles held by the majority of senior consultants in the firm, where were typically in large corporate environments.

\section{Organizational Knowledge Maintenance:}

As with both the individual and interactive levels, our analysis indicated that organizational level measures were required to actively maintain and refresh knowledge. While much of the emphasis in our example is placed on openness of task interpretation and creativity in solutions, it is equally clear that the reinforcement of defined existing knowledge was key to the maintenance process. For example, formalized training courses represented an organizational level feature that appeared to be designed for two key purposes. Firstly, they aided the new entrant in completing role demands based on existing organizational knowledge, thus contributing to how existing knowledge was utilized and refreshed. Secondly, they improved the knowledge base of the new entrant and supported the frame from which future new knowledge-based practices were undertaken. A similar purpose is evident in the use of expert support networks as a means to support knowledge flow. Discussing expert support of the new entrant, the CEO remarked: "At the level she is at, we throw her in the water and see if she can swim. But, there are experts around so you have got people around to throw a buoy if necessary" (CEO interview). Again, it was evident that this organizational ACAP antecedent interacted across levels by supporting individual knowledge acquisition, and by fostering an important platform for collaboration. 


\section{5}

\section{SUMMARY AND FURTURE DIRECTIONS FOR THE STUDY}

The objective of this preliminary study was to conceptualize knowledge absorption activities across microfoundational, interactive, and organizational levels. Our preliminary findings suggest that ACAP is constructed and maintained by a wide range of mundane and transformational activities occurring simultaneously and symbiotically across all levels of an organization. Our paper conceptualizes the antecedents of ACAP across three levels: individual, interactive, and organizational. We find that the individual agency of the new entrant and their ability to use new knowledge to go beyond existing organizational role boundaries is key to how new knowledge dissemination begins. We then find that these new practices must go through some form of translation in order that they can be released from the new entrant to others in the organization. It is these individual and interactive behaviors, rather than organizational strategies, that truly 'facilitate variation' (Lewin et al, 2011) in organizations, and account for the differences across firm-level ACAP (Felin et al., 2012). Finally, we find that organizational strategies aimed towards improving ACAP must seek to provide a favorable environment for micro-level knowledge creating activities. In particular, our findings emphasize the importance of a balance between structural and procedural support and a certain level of flexibility. This creates an environment that is supportive of individual agency, and that allows the existing unit to remain in a 'knowledge receiving' state.

We contribute to knowledge by answering research calls for the examination of ACAP at microfoundational level (Volberda et al., 2010). In particular, we contribute an empirically based conceptualization of the connections between ACAP levels. This paper represents the preliminary stages of a study aimed at portraying the dynamics of ACAP across multiple 
levels. Future research is aimed at studying microfoundational behavior and routine enactment across a temporal dimension using daily research diaries and observational data, the collection of which is ongoing. This will be key in examining the dynamic nature of the interactions that underpin ACAP. 


\section{5}

\section{BIBLIOGRAPHY}

Chalmers, D. M., \& Balan-Vnuk, E. 2012. Innovating not-for-profit social ventures: Exploring the microfoundations of internal and external absorptive capacity routines. International Small Business Journal.

Cohen, W. M., \& Levinthal, D. A. 1989. Innovation and learning: the two faces of R \& D. The economic journal, 99(397): 569-596.

Cohen, W. M., \& Levinthal, D. A. 1990. Absorptive capacity: a new perspective on learning and innovation. Administrative science quarterly: 128-152.

Cohen, W. M., \& Levinthal, D. A. 1994. Fortune favors the prepared firm. Management Science, 40(2): 227-251.

Colombo, M. G., \& Grilli, L. 2005. Founders' human capital and the growth of new technology-based firms: A competence-based view. Research policy, 34(6): 795-816.

Cope, J. 2005. Researching Entrepreneurship through Phenomenological Inquiry Philosophical and Methodological Issues. International Small Business Journal, 23(2): 163-189.

Dacin, M. T., Munir, K., \& Tracey, P. 2010. Formal dining at Cambridge colleges: Linking ritual performance and institutional maintenance. Academy of Management Journal, 53(6): 1393-1418.

Delmar, F., \& Shane, S. 2006. Does experience matter? The effect of founding team experience on the survival and sales of newly founded ventures. Strategic Organization, 4(3): 215-247.

Eisenhardt, K. M. 2013. Top management teams and the performance of entrepreneurial firms. Small Business Economics: 1-12.

Ensley, M. D., \& Hmieleski, K. M. 2005. A comparative study of new venture top management team composition, dynamics and performance between university-based and independent start-ups. Research Policy, 34(7): 1091-1105.

Feldman, M. S., \& Pentland, B. T. 2003. Reconceptualizing organizational routines as a source of flexibility and change. Administrative Science Quarterly, 48(1): 94-118. 
Felin, T., Foss, N. J., Heimeriks, K. H., \& Madsen, T. L. 2012. Microfoundations of routines and capabilities: Individuals, processes, and structure. Journal of Management Studies, 49(8): 1351-1374.

Finkelstein, S., \& Hambrick, D. 1996. Strategic Leadership: Top Executives and their Effects on Organisations. Minneapolis: West.

Forbes, D. P., Borchert, P. S., Zellmer - Bruhn, M. E., \& Sapienza, H. J. 2006. Entrepreneurial team formation: an exploration of new member addition. Entrepreneurship Theory and Practice, 30(2): 225-248.

Gimmon, E., \& Levie, J. 2010. Founder's human capital, external investment, and the survival of new high-technology ventures. Research Policy, 39(9): 1214-1226.

Gioia, D. A., \& Chittipeddi, K. 1991. Sensemaking and sensegiving in strategic change initiation. Strategic management journal, 12(6): 433-448.

Hambrick, D., \& Mason, P. 1984. Upper echelons: The organization as a reflection of its top managers. Academy of Management Review, 9: 193-206.

Hotho, J. J., Becker - Ritterspach, F., \& Saka - Helmhout, A. 2012. Enriching absorptive capacity through social interaction. British Journal of Management, 23(3): 383-401.

Jansen, J. J., Van Den Bosch, F. A., \& Volberda, H. W. 2005. Managing potential and realized absorptive capacity: how do organizational antecedents matter? Academy of Management Journal, 48(6): 999-1015.

Jones, O., \& Craven, M. 2001. Beyond the routine: innovation management and the Teaching Company Scheme. Technovation, 21(5): 267-279.

Kamm, J. B., \& Nurick, A. J. 1993. The stages of team venture formation: A decision-making model. Entrepreneurship Theory and Practice, 17: 17-17.

Kamm, J. B., Shuman, J. C., Seeger, J. A., \& Nurick, A. J. 1990. Entrepreneurial teams in new venture creation: A research agenda. Entrepreneurship Theory and Practice, 14(4): 7-17.

Lane, P. J., Koka, B. R., \& Pathak, S. 2006. The reification of absorptive capacity: a critical review and rejuvenation of the construct. Academy of Management Review, 31(4): 833-863. 
Lane, P. J., Salk, J. E., \& Lyles, M. A. 2001. Absorptive capacity, learning, and performance in international joint ventures. Strategic management journal, 22(12): 1139-1161.

Larson, A., \& Starr, J. A. 1993. A network model of organization formation. Entrepreneurship theory and practice, 17: 5-5.

Lewin, A. Y., Massini, S., \& Peeters, C. 2011. Microfoundations of internal and external absorptive capacity routines. Organization Science, 22(1): 81-98.

McAdam, R., Antony, J., Kumar, M., \& Hazlett, S. A. 2011. Absorbing new knowledge in small and medium-sized enterprises: A multiple case analysis of Six Sigma. International Small Business Journal.

Miles, M. B., \& Huberman, A. M. 1994. Qualitative data analysis: An expanded sourcebook: Sage.

Müller-Seitz, G. 2012. Absorptive and desorptive capacity-related practices at the network level - the case of SEMATECH. R\&D Management, 42(1): 90-99.

Neergaard, H. 2005. Networking activities in technology-based entrepreneurial teams. International Small Business Journal, 23(3): 257-278.

Neiswander, D. K., Bird, B. J., \& Young, P. L. 1987. Entrepreneurial hiring and management of early stage employees: Weatherhead School of Management, Case Western Reserve University.

Nelson, R. R., \& Winter, S. G. 1982. An Evolutionary Theory of Economic Change: Belknap Press of Harvard University Press.

Patton, D. 2013. Realising potential: The impact of business incubation on the absorptive capacity of new technology-based firms. International Small Business Journal.

Penrose, E. 1959. The theory of the growth of the firm.

Ritzer, G. 1983. The "McDonaldization" of society. Journal of American Culture, 6(1): 100-107.

Ritzer, G. 1998. The McDonaldization thesis: Explorations and extensions: Sage. 
Ruef, M., Aldrich, H. E., \& Carter, N. M. 2003. The structure of founding teams: Homophily, strong ties, and isolation among US entrepreneurs. American sociological review, 68(2): 195-222.

Spithoven, A., Clarysse, B., \& Knockaert, M. 2011. Building absorptive capacity to organise inbound open innovation in traditional industries. Technovation, 31(1): 10-21.

Taylor, F. W. 1911. The principles of scientific management. New York, 202.

Teece, D. J. 2007. Explicating dynamic capabilities: the nature and microfoundations of (sustainable) enterprise performance. Strategic Management Journal, 28(13): 13191350 .

Teece, D. J., Pisano, G., \& Shuen, A. 1997. Dynamic capabilities and strategic management. Strategic Management Journal, 18(7): 509-533.

Todorova, G., \& Durisin, B. 2007. Absorptive capacity: valuing a reconceptualization. Academy of Management Review, 32(3): 774-786.

Ucbasaran, D., Lockett, A., Wright, M., \& Westhead, P. 2003. Entrepreneurial founder teams: Factors associated with member entry and exit. Entrepreneurship Theory and Practice, 28(2): 107-128.

Van Den Bosch, F., Van Wijk, R., \& Volberda, H. W. 2006. Absorptive capacity: Antecedents, models and outcomes.

Volberda, H. W., Foss, N. J., \& Lyles, M. A. 2010. PERSPECTIVE-Absorbing the Concept of Absorptive Capacity: How to Realize Its Potential in the Organization Field. Organization Science, 21(4): 931-951.

West, G. P. 2007. Collective cognition: When entrepreneurial teams, not individuals, make decisions. Entrepreneurship Theory and Practice, 31(1): 77-102.

Zahra, S. A., \& George, G. 2002. Absorptive capacity: A review, reconceptualization, and extension. Academy of Management Review, 27(2): 185-203.

Zollo, M., \& Winter, S. G. 2002. Deliberate learning and the evolution of dynamic capabilities. Organization science, 13(3): 339-351. 


\section{5}

\section{Figure 1: Structure of Data Analysis}

A: New entrant uses existing knowledge to perform existing organizational role demands

B: New entrant learns how to perform unknown existing organizational role demands

C: New entrant performs existing organizational role demands in a new way

D: New entrant performs a new practice beyond existing organizational role boundaries

E: New practice recognized by others

F: New practice imitated, collectively repeated and performed

G: New practice collectively refined

H: New practice principles are labeled

I: New practice principles are formally recorded and disseminated

K: Ongoing communication of principles through technology e.g. email, messenger

L: Updating principles through social interaction within organizational setting

M: Updating principles through social interaction outside of organizational setting

P: Role design - wide scope for interpretation

Q: Incentives for new and effective solutions

R: Hierarchies, layers, and openness

$\mathrm{N}$ : Training in existing organizational knowledge e.g. inductions, courses, technical skills

O: Ongoing support through organizational expert networks
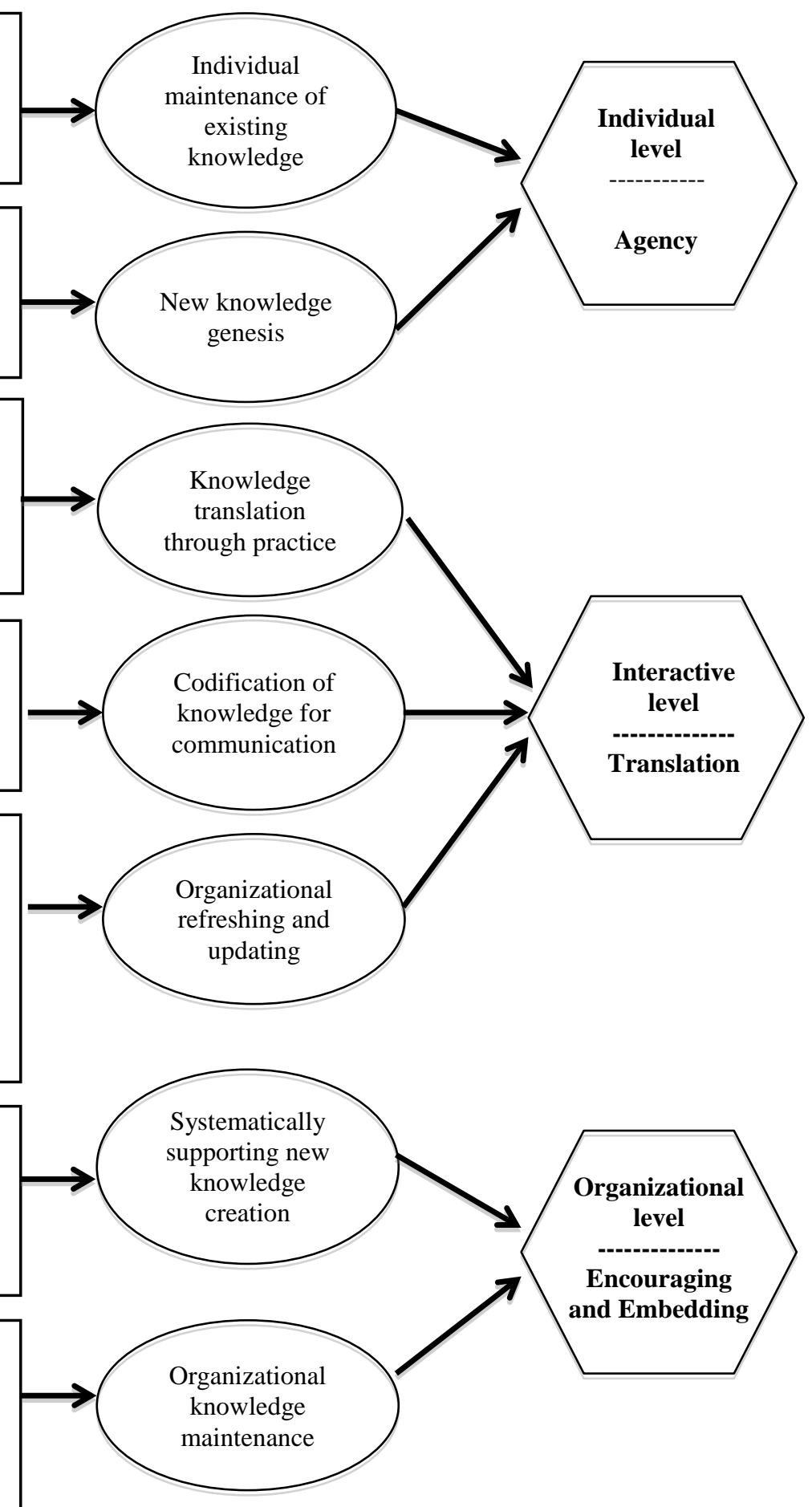
Table 1: Example Data Representing Theoretical Dimensions

\section{Theoretical Dimensions}

Individual Maintenance of Existing Knowledge:

A: New entrant uses existing knowledge to perform existing organizational role demands

B: New entrant learns how to perform unknown existing organizational role demands

\section{New Knowledge Genesis:}

C: New entrant performs existing organizational role demands in a new way

D: New entrant performs a new practice beyond existing organizational role boundaries

\section{Knowledge Translation through Practice:}

E: New practice recognized by others

F: New practice imitated, collectively repeated and performed

G: New practice collectively refined

\section{Codification of Knowledge for Communication:}

H: New practice principles are labeled

I: New practice principles are formally recorded

\section{Organizational Refreshing and Updating:}

$\mathrm{K}$ : Ongoing communication of principles through technology e.g. email, messenger

L: Updating principles through social interaction

\section{Representative Data}

"She has got about $80 \%$ of the knowledge she needs. The bulk of it is there. That's why we looked for specific career backgrounds. We want to know she could handle the core parts of the job (Existing CEO Interview)

"The remaining 20\% she has to learn and we need to make sure she does that" (Existing CEO Interview)

"It's always important to record of your actions during a consultancy project. It helps with timing and with accountability. I did this in a different way from the way the company used to. We've asked the other consultants to use this the new template now" (New Entrant Interview)

"I had lots of experience working on the 'inside' of a large bank. I was really the expert here, so it was me that designed, or I've started designing, the new customer services procedures for the banking clients that we have" (New Entrant Interview)

"It become obvious to the others on the project that there were certain new ways of doing things that I started that clearly worked. That's when we started trying to integrate them" (New Entrant Interview)

"He shadowed me in the beginning, then I sat at his desk, looked at what he was doing. It's very much repeating processes and getting familiar with processes" (New Entrant Interview)

"It's an ongoing process. We learn from each other and promote feedback until we were happy that the new procedures we working" (New Entrant Interview)

Project plan for Copenhagen based client (company documents)

"I put together weekly minutes as project reports. There's a lot of information in there. And whatever is in that document, it describes best practice as well"

(New Entrant Interview)

"We use email, Blackberry, sort of I mean text message, phone, all the usual" (New Entrant Interview)

“I don't think emails are really establishing a 
within organizational setting

M: Updating principles through social interaction outside of organizational setting

\section{Systematically Supporting New Knowledge Creation:}

$\mathrm{N}$ : Role design - wide scope for interpretation

O: Incentives for new and effective solutions

P: Hierarchies, layers, and openness

\section{Organizational Knowledge Maintenance:}

Q: Training in existing organizational knowledge e.g. inductions, courses, technical skills

R: Ongoing support through organizational expert networks relationship for me. Sending an email is more informing somebody of something, some weekly minutes and some updates, formalizing things in writing. But then there's, you know, I know that nowadays everything happens on email, but it's important to establish a relation with people. We have a balance" (New Entrant Interview)

"Yeah, over a drink we discuss work matters. Yeah, it's always a professional environment, so even if we're having a drink, we do discuss work matters" (New Entrant Interview)

"The scope was quite wide in the beginning and it was deliberately widened, so not set in stone" (New Entrant Interview)

"We had to find someone that was versatile enough to take on a range of assignments, one who is not scared to go into subjects they have not experienced" (Existing CEO Interview)

Incentive and profit sharing scheme (company documents)

"Yeah, you're more involved, you get to know the people better. We've got more input because the company is growing, everybody wants to grow the firm together. So you don't have that many hierarchy levels if you see what I mean, between yourself and like the CEO of ... I don't know ... UBS or whatever" (New Entrant Interview)

"Training? I would say trading system, the training involved what does the system do, what does it not do. The real functionalities around the analysis system" (New Entrant Interview)

"You've got different people here at the firm that are specialized in different subjects. And so then they're sort of experts in that specific domain. And if you've got a question relating to that you can go to that person and ask them" (New Entrant Interview) 